\title{
Isolation, identification and characterization of related substances in furbenicillin
}

\author{
Ye Tian, Yan Chang, Yan-Chun Feng, Dou-Sheng Zhang and Changqin Hu
}

Furbenicillin is a broad-spectrum semisynthetic penicillin with strong antibacterial activity against Gram-negative bacteria. In this study, three impurities in furbenicillin, including an unknown epimer, were determined. On the basis of a complete analysis of the spectrum (MS, ${ }^{1} \mathrm{H},{ }^{13} \mathrm{C}, 2 \mathrm{D}$ NMR and $\mathrm{CD}$ ) and the results of chemical methods, the unknown epimer impurity was identified as 10-epi-furbenicillin (impurity 1). Isolation and structure elucidation of impurity 1 was also reported here for the first time. The Journal of Antibiotics (2015) 68, 133-136; doi:10.1038/ja.2014.145; published online 22 October 2014

\section{INTRODUCTION}

The central molecular feature of penicillins consists of two fused rings (a four-membered $\beta$-lactamic ring and a five-membered thiazolidinic ring) with three chiral centers $(2 S, 5 R, 6 R)$. The addition of a 6 -acylamino side chain may result in the introduction of an additional chiral center, such as in amoxicillin, mezlocillin or furbenicillin.

Remarkably, the chiral center at C-6 or C-10 in the 6-side chain can isomerize under specific manufacturing or storing conditions. ${ }^{1-4}$ The crucial point is that alteration of the configuration of any of the chiral centers in 6-aminopenicillanic acid or in the 6-side chain can result in partial or total loss of activity. In the case of ampicillin, the C-10 epimers differ in aqueous solubility and activity; furthermore, the activity ratio $(R / S)$ ranges between two- and fivefold depending on the microorganism used for the test. ${ }^{5,6}$ Similarly, the antibiotic activity of the $R$-epimer of sulbenicillin is $\sim 40$ times more potent than that of the $S$-epimer. ${ }^{7}$ In contrast, in the case of carbenicillin, it was reported that the individual epimers display only minor differences in activity, and that they undergo rapid epimerization in solution. ${ }^{5,6}$

Furbenicillin, initially synthesized by the American company Bristol-Myers in 1969, is a broad-spectrum semisynthetic penicillin with strong antibacterial activity against Gram-negative bacteria, for example, Hemophilus influenza, Pseudomonas aeruginosa and Escherichia coli, and apparently in current clinical use in China for the treatment of the respiratory tract, urinary tract and intestinal tract infections caused by these Gram-negative bacteria. ${ }^{8-10}$ It was also shown that furbenicillin is more stable than carbenicillin, mezlocillin and azlocillin against the action of specific enzymes in P. aeruginosa. ${ }^{11}$ However, a nontrivial synthesis and the poor quality of the final product have strongly limited the clinical use of furbenicillin. Previous studies showed that furbenicillin for injection contained a relatively large amount of an unknown isomeric impurity. ${ }^{12,13}$ In this work, in order to provide the knowledge to improve the quality of the final product and the process of manufacture, three impurities, including an unknown isomer of furbenicillin in drug substance, were isolated, identified and characterized by liquid chromatography-MS, CD, NMR and chemical methods.

\section{RESULTS AND DISCUSSION}

Structure of the impurities

Our liquid chromatography measurements showed that there were three impurities with a relatively high content (Figures 1 and 2). The area percents of the impurity 1, 2 and $\mathbf{3}$ were $19.5 \%, 9.3 \%$ and $0.9 \%$, respectively. Reverse $>$ d-phase C18 HPLC on the $350 \mathrm{mg}$ of furbenicillin afforded $40.0 \mathrm{mg}$ of impurity $\mathbf{1}$ and $13.5 \mathrm{mg}$ of impurity 2 .

Impurity 1 showed ESI-MS peaks at $\mathrm{m} / \mathrm{z} 487[\mathrm{M}+\mathrm{H}]^{+}$and 509 $[\mathrm{M}+\mathrm{Na}]^{+}$. The data obtained with LC-MS/MS were virtually the same

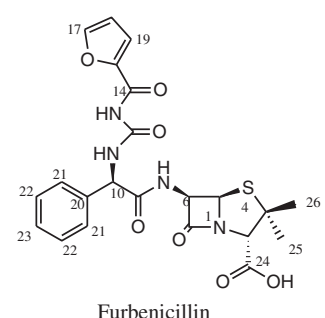

Furbenicillin

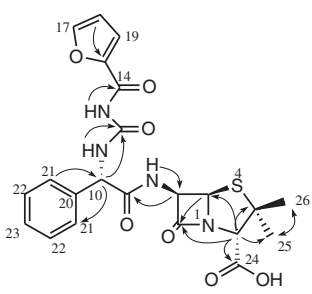

Impurity 1

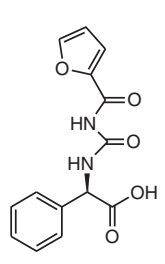

Impurity 2

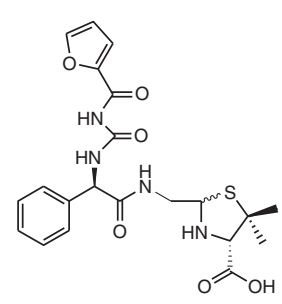

Impurity 3

Figure 1 Structure of furbenicillin and impurities 1, 2 and $\mathbf{3}$ (arrows on impurity $\mathbf{1}$ show HMBC correlations). 
for impurity 1 and furbenicillin (Figure 3), confirming that impurity 1 is an isomer of furbenicillin. Impurity $\mathbf{1}$ was isolated according to the method described in section 2.2.2 and characterized using CD, NMR and chemical methods. The ${ }^{1} \mathrm{H}-\mathrm{NMR}$ spectrum of impurity $\mathbf{1}$ (Table 1) displayed resonance for a monosubstituted benzene ring

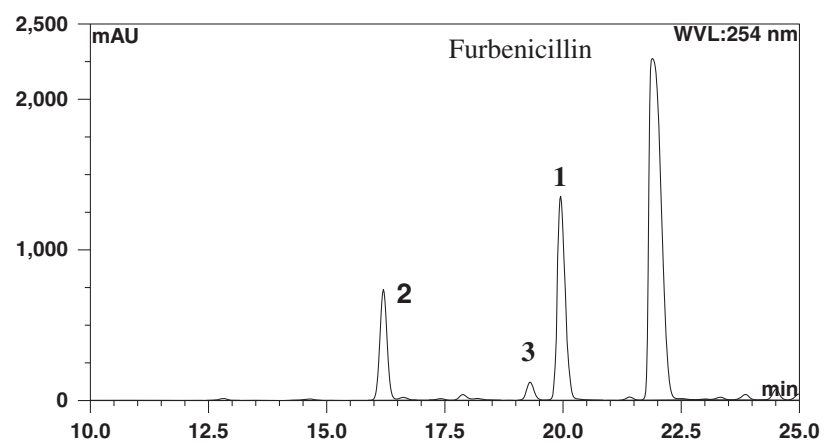

Figure 2 HPLC chromatograms of furbenicillin (1: 10-epi-furbenicillin (impurity 1) 19.5\%; 2: impurity 2 9.3\%; 3: impurity $30.9 \%$ ).
$\left(\delta_{\mathrm{H}} 7.45(2 \mathrm{H}, \mathrm{d}, J=7.2 \mathrm{~Hz}, \mathrm{H}-21), 7.39(2 \mathrm{H}, \mathrm{t}, J=7.2 \mathrm{~Hz}, \mathrm{H}-22)\right.$ and $7.32(1 \mathrm{H}, \mathrm{t}, J=7.2 \mathrm{~Hz}, \mathrm{H}-23)]$, a monosubstituted furan $\operatorname{ring}\left(\delta_{\mathrm{H}} 8.00\right.$ $(1 \mathrm{H}, \mathrm{d}, J=0.6 \mathrm{~Hz}, \mathrm{H}-17), 6.71(1 \mathrm{H}, \mathrm{dd}, J=0.6,3.6 \mathrm{~Hz}, \mathrm{H}-18)$ and 7.65 $(1 \mathrm{H}, \mathrm{d}, J=3.6 \mathrm{~Hz}, \mathrm{H}-19)]$, a penicillin nucleus $\left(\delta_{\mathrm{H}} 4.23(1 \mathrm{H}, \mathrm{s}, \mathrm{H}-2)\right.$, $5.50(1 \mathrm{H}, \mathrm{d}, J=4.2 \mathrm{~Hz}, \mathrm{H}-5), 5.41(1 \mathrm{H}, \mathrm{dd}, J=4.2,7.8 \mathrm{~Hz}, \mathrm{H}-6), 1.48$ $(3 \mathrm{H}, \mathrm{s}, \mathrm{H}-25)$ and $1.62(3 \mathrm{H}, \mathrm{s}, \mathrm{H}-26))$. Besides proton-bearing carbon resonances corresponding to the above units, the ${ }^{13} \mathrm{C}$ NMR and the DEPT spectra showed resonances for three quaternary carbons. The comparison of the NMR data of impurity $\mathbf{1}$ and furbenicillin (Table 1) revealed that the order of the resonances for H-5 and H-6 in impurity 1 has an inverse pattern $\left(\delta_{\mathrm{H}-5}>\delta_{\mathrm{H}-6}\right)$, which in turn is different from the one of common penicillin $\left(\delta_{\mathrm{H}-6}>\delta_{\mathrm{H}-5}\right) ;{ }^{8-10}$ in addition, $\mathrm{H}-5, \mathrm{H}-25$, H-26, H-6 and H-10 of impurity 1 were shifted significantly by $\delta_{\Delta \mathrm{H}}$ $+0.11,+0.08,+0.07,-0.14$ and -0.07 p.p.m., respectively, compared with those in furbenicillin. This structure of impurity 1 was further supported by analysis of the $2 \mathrm{D}$ NMR data from HSQC, ${ }^{1} \mathrm{H}-{ }^{1} \mathrm{H}$ COSY and $\mathrm{HMBC}$ experiments. In particular, the correlations between $\mathrm{H}-2$ and C-3, C-5, C-24, C-25, C-26, H-5 and C-6, C-7, H-6 and C-5, H-8 and $\mathrm{C}-6$, and $\mathrm{H}_{3}-25$ and $\mathrm{C}-2, \mathrm{C}-26$ from the $\mathrm{HMBC}$ experiments demonstrated the moiety of the 6 -aminopenicillanic acid penicillin
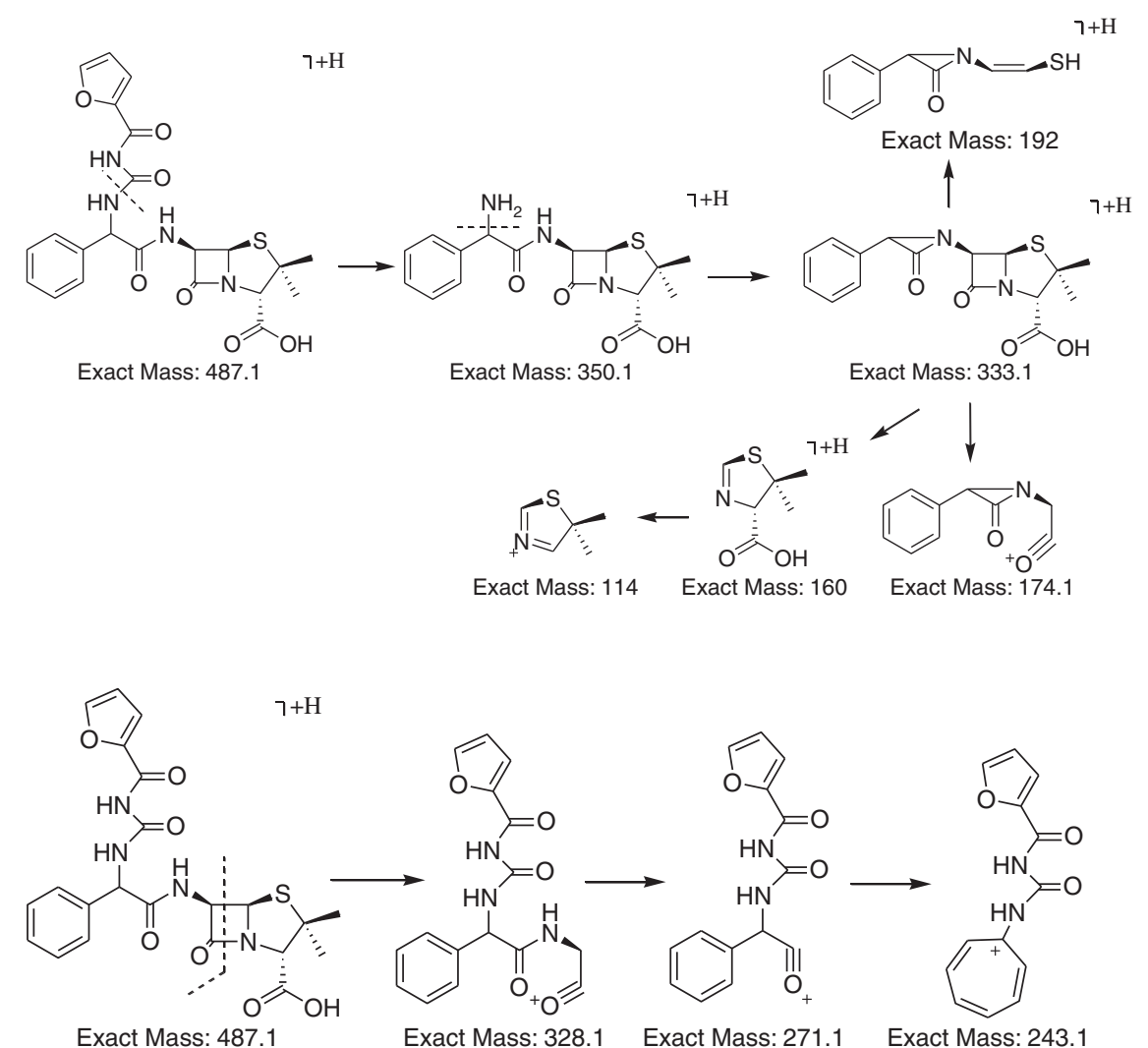<smiles>CCOC(C)C(C=O)NC(=O)NC(=O)c1ccco1</smiles><smiles>O=C(NC(=O)c1ccco1)Nc1ccccc1</smiles>

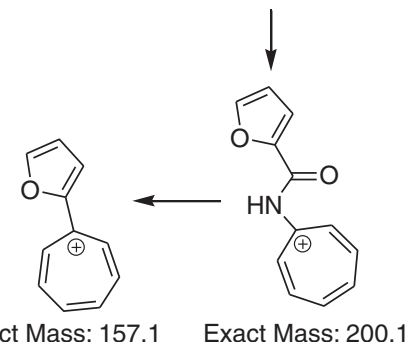

Figure 3 Cleavage pathway of furbenicillin and impurity 1 . 
Table 1 NMR Data $(\delta)$ of furbenicillin and impurity 1 in DMSO- $d_{6}{ }^{a}$

\begin{tabular}{|c|c|c|c|c|}
\hline \multirow[b]{2}{*}{ No. } & \multicolumn{2}{|l|}{ Furbenicillin } & \multicolumn{2}{|l|}{ Impurity 1} \\
\hline & $\delta_{H}$ & $\delta_{C}$ & $\delta_{H}$ & $\delta_{C}$ \\
\hline 2 & $4.20,1 \mathrm{H}, \mathrm{s}$ & 70.4 & $4.23,1 \mathrm{H}, \mathrm{s}$ & 70.4 \\
\hline 3 & - & 63.7 & - & 63.9 \\
\hline 5 & $5.39,1 \mathrm{H}, \mathrm{d}, J=4.2$ & 67.0 & $5.50,1 \mathrm{H}, \mathrm{d}, J=4.2$ & 67.1 \\
\hline 6 & $5.55,1 \mathrm{H}, \mathrm{dd}, J=4.2 ; 7.8$ & 58.1 & $5.41,1 \mathrm{H}, \mathrm{dd}, J=4.2 ; 7.8$ & 58.7 \\
\hline 7 & - & 173.2 & - & 172.7 \\
\hline 8 & $9.31,1 \mathrm{H}, \mathrm{d}, J=7.8$ & - & $9.35,1 \mathrm{H}, \mathrm{d}, \mathrm{J}=7.8$ & - \\
\hline 9 & - & 169.6 & - & 169.7 \\
\hline 10 & $5.75,1 \mathrm{H}, \mathrm{d}, J=7.8$ & 55.7 & $5.68,1 \mathrm{H}, \mathrm{d}, J=7.8$ & 55.8 \\
\hline 11 & $9.39,1 \mathrm{H}, \mathrm{d}, J=7.8$ & - & $9.35,1 \mathrm{H}, \mathrm{d}, J=7.8$ & - \\
\hline 12 & - & 152.3 & - & 152.2 \\
\hline 13 & $10.74,1 \mathrm{H}, \mathrm{s}$ & - & $10.73,1 \mathrm{H}, \mathrm{s}$ & - \\
\hline 14 & - & 158.4 & - & 158.4 \\
\hline 15 & - & 145.3 & - & 145.3 \\
\hline 17 & $8.00,1 \mathrm{H}, \mathrm{d}, J=1.2$ & 147.8 & $8.00,1 \mathrm{H}, \mathrm{d}, J=0.6$ & 147.8 \\
\hline 18 & $6.71,1 \mathrm{H}, \mathrm{dd}, J=1.2 ; 3.6$ & 112.4 & $6.71,1 \mathrm{H}, \mathrm{dd}, J=0.6 ; 3.6$ & 112.4 \\
\hline 19 & $7.66,1 \mathrm{H}, \mathrm{d}, J=3.6$ & 117.4 & $7.65,1 \mathrm{H}, \mathrm{d}, J=3.6$ & 117.4 \\
\hline 20 & - & 138.2 & - & 138.4 \\
\hline 21 & $7.43,2 \mathrm{H}, \mathrm{d}, J=7.8$ & 126.5 & $7.45,2 \mathrm{H}, \mathrm{d}, J=7.2$ & 126.7 \\
\hline 22 & $7.36,2 \mathrm{H}, \mathrm{t}, \mathrm{J}=7.8$ & 128.4 & $7.39,2 \mathrm{H}, \mathrm{t}, \mathrm{J}=7.2$ & 128.5 \\
\hline 23 & $7.31,1 \mathrm{H}, \mathrm{d}, J=7.8$ & 127.8 & $7.32,1 \mathrm{H}, \mathrm{d}, J=7.2$ & 128.0 \\
\hline 24 & - & 168.9 & - & 168.9 \\
\hline 25 & $1.40,3 \mathrm{H}, \mathrm{s}$ & 26.6 & $1.48,3 \mathrm{H}, \mathrm{s}$ & 26.7 \\
\hline 26 & $1.55,3 \mathrm{H}, \mathrm{s}$ & 30.3 & $1.62,3 \mathrm{H}, \mathrm{s}$ & 30.3 \\
\hline
\end{tabular}

a Data $(\delta)$ were measured at $600 \mathrm{MHz}$. Coupling constants $(\mathcal{J}$ are given in $\mathrm{Hz}$. The assignments were based on DEPT, ${ }^{1} \mathrm{H}-{ }^{1} \mathrm{H}$ COSY, HSQC and HMBC experiments.

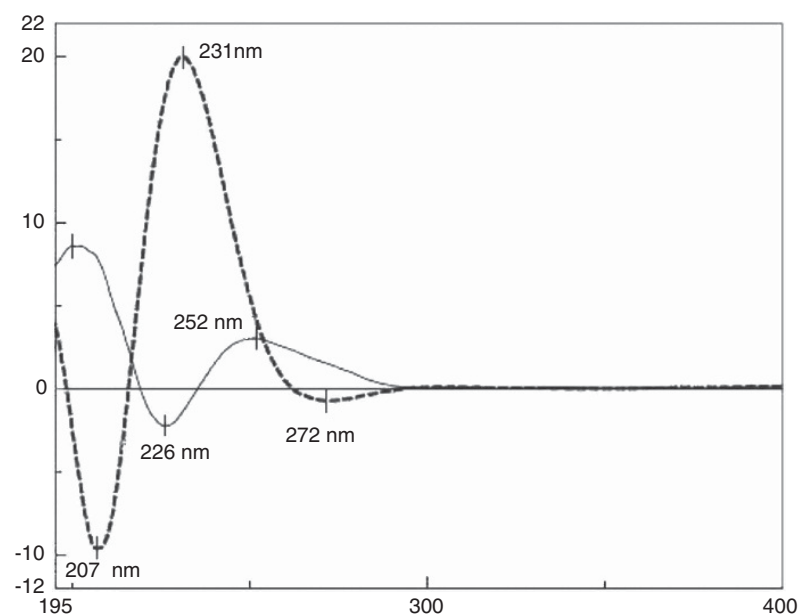

Figure $4 \mathrm{CD}$ spectrum of furbenicillin and impurity 1 [-: furbenicillin; 10-epi-furbenicillin (impurity 1)].

nucleus. The correlations between $\mathrm{H}-10$ and $\mathrm{C}-12, \mathrm{C}-21, \mathrm{H}-11$ and C-12, H-18 and C-15, and H-6 and C-9 demonstrated the structure and connection pattern of the side chain, confirming that impurity $\mathbf{1}$ is characterized by a planar structure identical to that of furbenicillin (Figure 1).

The $J_{\mathrm{H}-5, \mathrm{H}-6}$ value in the ${ }^{1} \mathrm{H}$ NMR spectrum of impurity 1 indicated that $\mathrm{H}-5$ and $\mathrm{H}-6$ are in cofacial positions. ${ }^{8-10}$ In an NOE experiment of impurity 1, irradiation of $\mathrm{H}-2$ enhanced the intensity of the $\mathrm{H}_{3}-26$ signals. Furthermore, the $\mathrm{H}-2$ signals were enhanced upon irradiation of $\mathrm{H}_{3}-26$, and irradiation of $\mathrm{H}-5$ enhanced the intensities of H-6.

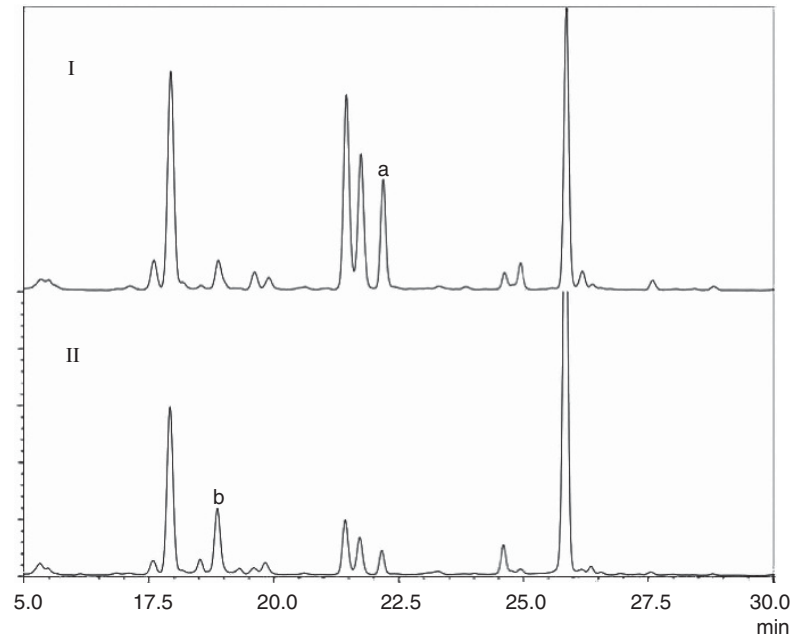

Figure 5 HPLC chromatograms of Marfey's reaction of furbenicillin(I) and impurity 1(II). a: Derivatives of D-amino acid; b: Derivatives of L-amino acid.

Table 2 MIC values of furbenicillin and impurity 1

\begin{tabular}{llc}
\hline Sample & Bacterium & MIC50 \\
\hline Furbenicillin & Staphylococcus aureus (ATCC 25923) & 4 \\
Impurity 1 & - & $>256$ \\
Furbenicillin & Pseudomonas aeruginosa (ATCC 27853) & 4 \\
Impurity 1 & - & $>256$ \\
\hline
\end{tabular}

These finding showed that the structure of impurity $\mathbf{1}$, excluding the 6-side chain, has the same relative configuration as furbenicillin (Supplementary Figures S4 and S11 electronic Supplementary Material).

The CD spectrum of furbenicillin showed a positive Cotton effect at $231 \mathrm{~nm}$ and a negative Cotton effect at $207 \mathrm{~nm}\left(n \rightarrow \pi^{\star}\right.$ transition of the $\beta$-lactam ring $)^{14}$ and a negative Cotton effect at $272 \mathrm{~nm}\left(n \rightarrow \pi^{*}\right.$ transition of 6-side chian).The predominant difference between the CD data for impurity 1 and furbenicillin (Figure 4) is that for impurity 1, the Cotton effect due to the 6-aminopenicillanic acid shifted to longer wavelengths by about $20 \mathrm{~nm}$, and the Cotton effect in impurity 1 due to the 6-side chain $(\sim 272 \mathrm{~nm})$ was positive in contrast. This suggests that impurity $\mathbf{1}$ is an epimer of furbenicillin with the opposite configuration at C-10.

The absolute configuration of the phenylglycine residue was further confirmed after hydrolysis of impurity $\mathbf{1}$ and derivatization HPLC analysis by using Marfey's method. ${ }^{15,16}$ The 1-fluoro-2,4-dinitrophenyl-5-L-alanine amide derivative of the hydrolyzate of impurity 1 gave the same HPLC retention time as that of the authentic L-phenylglycine (Figure 5), which showed that the phenylglycine residue in impurity 1 must be assigned the L-configuration. Thus, on the basis of the foregoing evidence, the structure of impurity $\mathbf{1}$ was established as 10-epi-furbenicillin.

Impurity 2 showed ESI-MS peak at $\mathrm{m} / \mathrm{z} 311[\mathrm{M}+\mathrm{Na}]^{+}$. By comparation of MS, CD and NMR data with furbenicillin (Supplementary Figures S12-S15 electronic Supplementary Material), impurity 2 was determined to be (R)-2-(3-furan-2-carbonylureido)-2phenylacetic acid. ${ }^{13}$ Impurity 3 showed ESI-MS peaks at $\mathrm{m} / \mathrm{z} 461$ $[\mathrm{M}+\mathrm{H}]^{+}$and $483[\mathrm{M}+\mathrm{Na}]^{+}$. By comparation of MS data with furbenicillin (Supplementary Figures S16 and S17 electronic 
Supplementary Material), impurity 3 was determined to be $5(R / S)$ furbenicillin penicilloic acid, which represents a common degradation of penicillins. ${ }^{17,18}$

\section{MIC test}

The antibacterial activities of furbenicillin and impurity 1 were determined by MIC tests. Impurity 1 was found to be inactive against Staphylococcus aureus (ATCC 25923) and P. aeruginosa (ATCC 27853) (Table 2).

\section{CONCLUSIONS}

In this work, a complete spectral analysis $\left(\mathrm{MS},{ }^{1} \mathrm{H},{ }^{13} \mathrm{C}, 2 \mathrm{D}\right.$ NMR and $\mathrm{CD}$ ) and other chemical methods were employed to identify three impurities, including a previously unknown epimer, in the furbenicillin drug substance.

Stereoisomers are typically recognized by the body as distinct chemical entities, and they exhibit different pharmacological activities, toxicities and pharmacokinetics. The epimerization at $\mathrm{C} 10$ of furbenicillin can result in the decrease of antibacterial potency.

\section{MATERIALS AND METHODS}

\section{Chemicals and reagents}

The following reagents were used in our study: furbenicillin sodium substance from Bocom Pharmaceutical Co., Ltd, Taiyuan, China; acetonitrile and methanol from Chromatographic Pure, Fisher (Fairlawn, NJ, USA); 1-fluoro-24-dinitrophenyl-5-L-alanine amide and all other reagents $\left(\mathrm{CH}_{3} \mathrm{COCH}_{3}\right.$, $\mathrm{CH}_{3} \mathrm{COOH}, \mathrm{KH}_{2} \mathrm{PO}_{4}, \mathrm{H}_{3} \mathrm{PO}_{4}$ and $\mathrm{Na}_{2} \mathrm{CO}_{3}$ ) that were commercially obtained were of analytical reagent grade. All solutions were prepared in doubledistilled water.

\section{Instruments}

The following instruments were used in our study: a Dionex P680 HPLC pump, a Dionex ASI-100 autosampler, a PDA-100 diode-array detecto (Dionex, Sunnyvale, CA, USA), Q-Trap 3200 (AB Sciex, Foster City, CA, USA), a Varian INOVA $600 \mathrm{MHz}$ NMR spectrometer (Varian, Palo Alto, CA, USA), and a JASCO-815 CD spectrometer (Jasco, Japan).

\section{LC-MS spectrometry}

Chromatographic conditions. A mobile phase containing methanol$10 \mathrm{mmoll}^{-1}$ ammonium formate (pH 3.0, adjusted with $\left.\mathrm{CH}_{3} \mathrm{COOH}\right)(55: 45$, $\mathrm{v} / \mathrm{v}$ ) was used at a flow rate of $1.0 \mathrm{ml} \mathrm{min}{ }^{-1}$. The CAPCELL PAK-C18 column $(250 \times 4.6 \mathrm{~mm}$ i.d., $5.0 \mu \mathrm{m})$ was maintained at $25^{\circ} \mathrm{C}$. Samples were prepared in the mobile phase at a concentration of $1.0 \mathrm{mg} \mathrm{ml}^{-1}$. The injection volume was $10 \mu \mathrm{l}$. UV detection was performed from 200 to $400 \mathrm{~nm}$ (extraction: $254 \mathrm{~nm}$ ).

MS conditions. The mass spectra of impurities of furbenicillin were obtained using the following optimized MS conditions. ESI was used in positive ionization mode, the declustering potential was $15 \mathrm{~V}$, the entrance potential was $10 \mathrm{~V}$ and the collision energy was $15 \mathrm{~V}$. The curtain gas, ion-source gas 1 , and ion-source gas 2 flowed at 20.0,65.0 and $60.0 \mathrm{lh}^{-1}$, respectively; the ion spray voltage (IS) was $5500 \mathrm{~V}$, and the temperature (TEM) was $500.0^{\circ} \mathrm{C}$, with the interface heater on. Enhanced MS and enhanced product ion spectra were acquired from m/z 50 to m/z 200 in 0.1 a.m.u. steps with a 2.0-s dwell time. The Analyst software (version 1.5.1, AB Sciex) was used for data acquisition and processing.

Preparative liquid chromatography. A Grace Prevail C18, $5 \mu \mathrm{m}, 10 \mathrm{~mm} \times$ $250 \mathrm{~mm}$ i.d. was used for the separation. The column eluent was monitored at a wavelength of $254 \mathrm{~nm}$. Different mixtures of $0.01 \mathrm{moll}^{-1} \mathrm{KH}_{2} \mathrm{PO}_{4}$ solution $(\mathrm{pH}=3.2)$, adjusted with phosphoric acid, (mobile phase $\mathrm{A})$ and methanol (mobile phase B) were used as the mobile phases (A:B, 48:52) at a flow rate of $2.0 \mathrm{ml} \mathrm{min}^{-1}$

NMR measurements. NMR measurements were carried out on a Varian INOVA instrument (for both ${ }^{1} \mathrm{H}$ and ${ }^{13} \mathrm{C}$ ) at $25^{\circ} \mathrm{C}$ in DMSO- $d_{6}$. The ${ }^{1} \mathrm{H}$ and ${ }^{13} \mathrm{C}$ chemical shifts values are reported on the $\delta$ scale in p.p.m. relative to TMS $(\delta=0.00$ p.p.m. $)$ and DMSO- $d_{6}(\delta=39.5$ p.p.m. $)$ as the internal standards, respectively.

MIC determination. The McFarland bacterial suspension was prepared with sterile normal saline using the Clinical and Laboratory Standards Institute agar dilution method. ${ }^{19}$ The suspensions were diluted with sterile normal saline in a proportion of 1:100. The final solutions were inoculated onto the surface of a Müller-Hinton agar plate containing sites with different furbenicillin and impurity 1 concentrations using multi-point inoculators. After culturing of these samples at $35 \pm 1^{\circ} \mathrm{C}$ for $22-24 \mathrm{~h}$, the MIC values were recorded.

\section{ACKNOWLEDGEMENTS}

This study was supported by Youth development research foundation of NIFDC (2013NA2).

1 Jiang, Y., Zhang, Z. F. \& Wang, H. Isomeric impurity research and quality control of B-lactam antibiotics. Chin. J. Antibiot. 35, 561-566 (2010).

2 Busson, R. \& Vanderhaeghe, H. Preparation and isomerization of 5-epibenzylpenicillins. J. Org. Chem. 41, 2561-2565 (1976)

3 Wiitala, K. W., Cramer, C. J. \& Hoye, T. R. Comparison of various density functional methods for distinguishing stereoisomers based on computed $1 \mathrm{H}$ or $13 \mathrm{C}$ NMR chemical shifts using diastereomeric penam $\beta$-lactams as a test set. Magn. Reson. Chem. 45 819-829 (2007).

4 Bird, A. E., Steele, B. R., Boles, M. O. \& Gane, P. A. C. Nuclear magnetic resonance and circular dichroism of penicillins derived from disubstituted acetic acids. J. Chem. Soc., Perkin Trans. 1, 563-569 (1982)

5 Hutt, A. G. \& O'Grady, J. Drug chirality: a consideration of the significance of the stereochemistry of antimicrobial agents. J. Antimicrob. Chemother. 37, 7-32 (1996).

6 Nayler, J. H. Advances in penicillin research. Adv. Drug Res. 7, 1-105 (1973)

7 Nomura, H. et al. Studies on diastereomers of sulbenicillin by nuclear magnetic resonance. J. Takeda Res. Lab. 31, 442-452 (1972).

8 Bodey, G. P. \& Stewart, D. In vitro studies of semisynthetic alpha(substituted-ureido) penicillins. Appl. Microbiol. 21, 710-717 (1971).

9 Jiatai, L., Zhongmin, S., Tieying, L., Lingjia, M. \& Mei, F. Furbenicillin and its antibacterial activity. Chin. Med. J. 92, 185-192 (1979).

$10 \mathrm{Ma}$, Y. Z., Liu, Y. X., Zhou, Y. P., Mei, W. J. \& She, Z. G. Improved synthesis of furbenicillin sodium. Chin. J. Med. Chem. 16, 51-53 (2006).

$11 \mathrm{Li}$, J. T. \& Williams, J. D. Comparative activity of furbenicillin and carbenicillin-like compounds. J. Antimicrob. Chemother. 9, 171-181 (1982).

12 Zhang, J., Jiang, J. \& Gao, Y. Determination of Furbenicillin Sodium related substances and in vitro antibacterial activity comparison. Chin. Pharm. 19, 34-35 (2010).

13 Zhang, J., Jiang, J. \& Gao, Y. HPLC-Electrospray Ionization-Mass spectrum analysis of Furbenicillin sodium and its related substances. Chin. Pharm. 18, 16-17 (2009).

14 Elks J. (ed.). Recent Advances in the Chemistry of $\beta$-Lactam Antibiotics. Special Publication No. 28, 304-313 (The Chemical Society: London, UK, 1976).

15 Gan, M. et al. Polyketides with New Delhi metallo- $\beta$-lactamase 1 inhibitory activity from Penicillium sp. J. Nat. Prod. 76, 1535-1540 (2013).

16 Bhushan, R. \& Brückner, H. Marfey's reagent for chiral amino acid analysis: a review. Amino Acids 27, 231-247 (2004).

17 Robinson-Fuentes, V. A., Jefferies, T. M. \& Branch, S. K. Degradation pathways of ampicillin in alkaline solutions. J. Pharm. Pharmacol. 49, 843-851 (1997).

18 Aboul Khier, A., Blaschke, G. \& El Sadek, M. Determination of some penicillin derivatives using high performance liquid chromatography. Anal. Lett. 17, 1659-1666 (1984).

19 Clinical and Laboratory Standards Institute Methods for dilution antimicrobial susceptibility tests for bacteria that grow aerobically; approved standard-8th edition. Report No.:12M07-A7 (2009)

Supplementary Information accompanies the paper on The Journal of Antibiotics website (http://www.nature.com/ja) 